\title{
HOW TO LINK CORPORATE SOCIAL RESPONSIBILITY AND CREATING SHARED VALUES WITH TRAFFIC SAFETY
}

\author{
RYOSUKE ANDO, YASUHIRO MIMURA, SHIROU TSUBOI \& MAKOTO ISHII \\ TTRI (Toyota Transportation Research Institute), Japan
}

\begin{abstract}
The aim of the present study was to explore the effects of the corporate social responsibility (CSR) in combination with the creating shared values (CSV) on the traffic conditions with a focus on improving the traffic safety and the elderly mobility in Aichi Prefecture of Japan. A questionnaire survey targeting 300 companies was conducted during October and November 2018. The industries and companies were classified based on the number of employees and company scale. The aggregation analysis was performed on the collected data in order to get ideas that could be useful for devising traffic safety countermeasures. The current study summarizes a handful of effective traffic safety countermeasures that can result in the accident reduction in Aichi and ultimately in Japan. The considerable effective countermeasures include providing safety education and information to the employees, providing information on effects of the Advanced Driver Assistance System (ADAS) vehicle, supplying subsidies for changing to the ADAS vehicles and promoting the CSR and the CSV. All countermeasures are expected to be realized in Aichi so as to reduce the traffic accidents by 2030 .

Keywords: CSR, CSV, traffic safety, effective countermeasures, elderly mobility, ADAS.
\end{abstract}

\section{INTRODUCTION}

In Japan, as shown in Table 1 [1], [2], the number of traffic accidents are continuously decreasing since 2015 and consequently that the traffic accidents fatalities and the fatalities per 100,000 people are also decreasing proportionally. However, there still exists a big gap with the target fatalities per year that is 2,500 in 2020 [1]. Amongst all 47 prefectures of Japan, the Aichi prefecture had been ranked worst for traffic accident fatalities for 17 years until 2018. However, this number was reduced to total of 156 fatalities in 2019, 12 fatalities less than Chiba Prefecture which ranked the worst. One of the important factors that resulted in the reduction of accidents was that the traffic policymakers of Aichi prefecture conducted a serious study named "the grand design of traffic safety countermeasures for elderly people in Aichi" in 2018 (see details in [3], [4]). Many practical initiatives and steps were taken ever since based on the finding of the aforementioned study.

Nagoya City is the capital of Aichi prefecture and the fourth most populated in Japan. Aichi is very famous with its industrial power taking automobile industry as the representative of this prefecture. Fig. 1 shows the industry production amounts of all prefectures of Japan in 2016. The industry production amounts of Aichi was three times comparing to that of Kanagawa, Shizuoka, Osaka and Hyogo which consist of the second group. By considering the above background in Aichi and that the traffic safety is a very serious social threat, we have tried to find some countermeasures or ideas in the viewpoints of the CSR (corporate social responsibility) and the CSV (creating shared values) during the study in 2018.

As the representative case study related with the traffic safety education in Japan, Shinken Shimizu, a lawyer, has summarized its importance for a company [5]. In Aichi prefecture, Aichi Safe Driving Management Association has been set up by many companies and 
Table 1: Number of traffic accidents and fatalities in Japan.

\begin{tabular}{|c|c|c|c|}
\hline Year & $\begin{array}{c}\text { No. of traffic } \\
\text { accidents }\end{array}$ & $\begin{array}{c}\text { Fatalities caused } \\
\text { by accidents }\end{array}$ & $\begin{array}{c}\text { Fatalities per } \\
100,000 \text { people }\end{array}$ \\
\hline 2015 & 536,899 & 4,117 & 3.24 \\
\hline 2016 & 499,201 & 3,904 & 3.07 \\
\hline 2017 & 472,165 & 3,694 & 2.91 \\
\hline 2018 & 430,601 & 3,532 & 2.79 \\
\hline 2019 & 381,002 & 3,215 & 2.54 \\
\hline
\end{tabular}

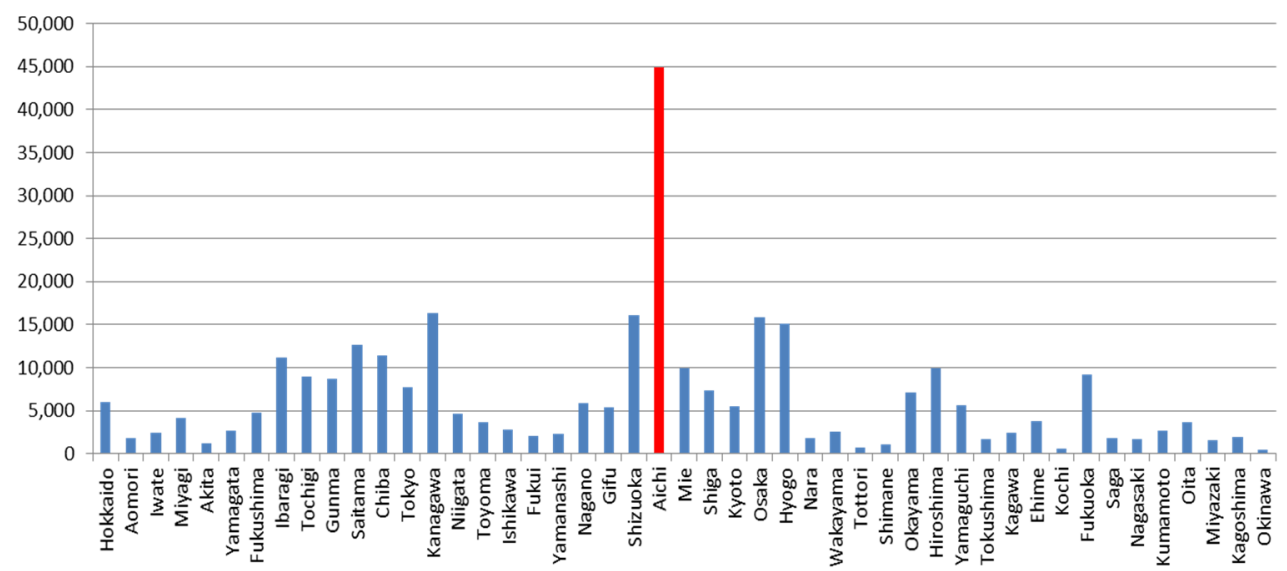

Figure 1: Industry production amounts of all prefecture in Japan (billion Yen, 2016).

supported by the Aichi Prefecture Policy Headquarters to promote the corporate traffic safety education [6]. Being different with the conventional traffic safety countermeasures, the government has been promoted the ADAS (Advanced Driver Assistance System) vehicles by the subsidy [7]. Some insurance companies, such as Aioi Nissay Dowa Insurance [8], have developed some insurance plans to promote the new safety vehicle technologies by reducing the costs.

Under the above social circumstance, in this paper, the survey is reported so that some hints for finding effective traffic safety countermeasures can be obtained for other prefectures in Japan and other countries in the world. As the name of the "grand design" suggests, the main target group was elderly people. This is because the share of elderly fatalities caused by traffic accidents is recorded more than $50 \%$ in the last eight years and has shown an increasing trend as illustrated in Fig. 2.

\section{OUTLINE OF THE SURVEY}

The survey was carried out from mid-October to mid-November 2018. Three hundred companies in Aichi Prefecture, the corporate members of Aichi Safe Driving Management Association, were taken as the target. Although there are more than 10,000 members at the association in total, the answers have been collected from 300 companies following the principle first-come-first-service by considering the very tight schedule and the statistical significance of the collected data. 


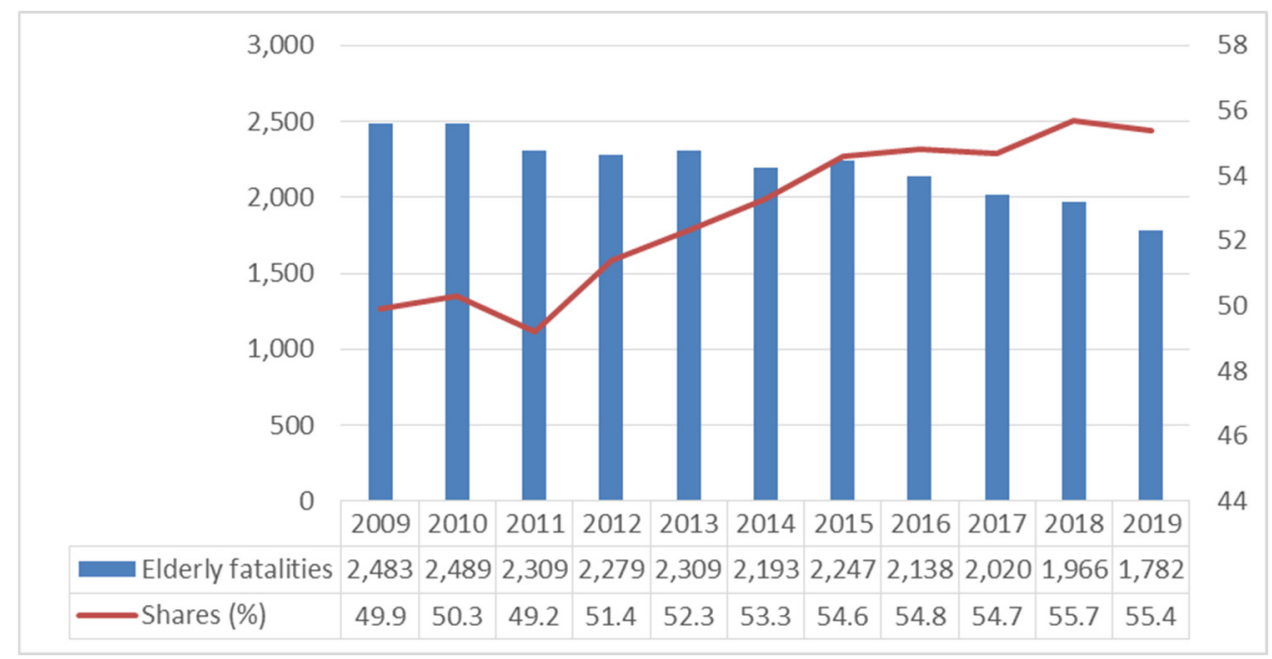

Figure 2: Numbers and shares of traffic accident elderly fatalities in Japan.

The survey includes: (A) the corporate characteristics, such as the number of employees and the industry classification; (B) what they did/do relating with the CSR and the CSV; and (C) acceptance on the countermeasures proposed or being under discussion for improving the traffic safety situation in Aichi Prefecture. The survey method was made emails. At first, the survey sheets were sent by the mailing list of the association and then the answers were collected by emailing back or the considerable approaches that the companies after consulting with us.

The situation of elderly employees (being 65 years or older) is summarized in Fig. 3. Although most of companies have less than $10 \%$ elderly employees, five companies have elderly employees being higher than $50 \%$. These trends reflected the social characteristic of Japan that is an aged society.

Fig. 4 shows the classification of 300 companies based on their number of employees. The results revealed that 118 companies, being nearly $40 \%$ of the total companies, have 300 or more employees. While, 74 companies, about $25 \%$, have less than 50 employees and 108 companies have employees between them.

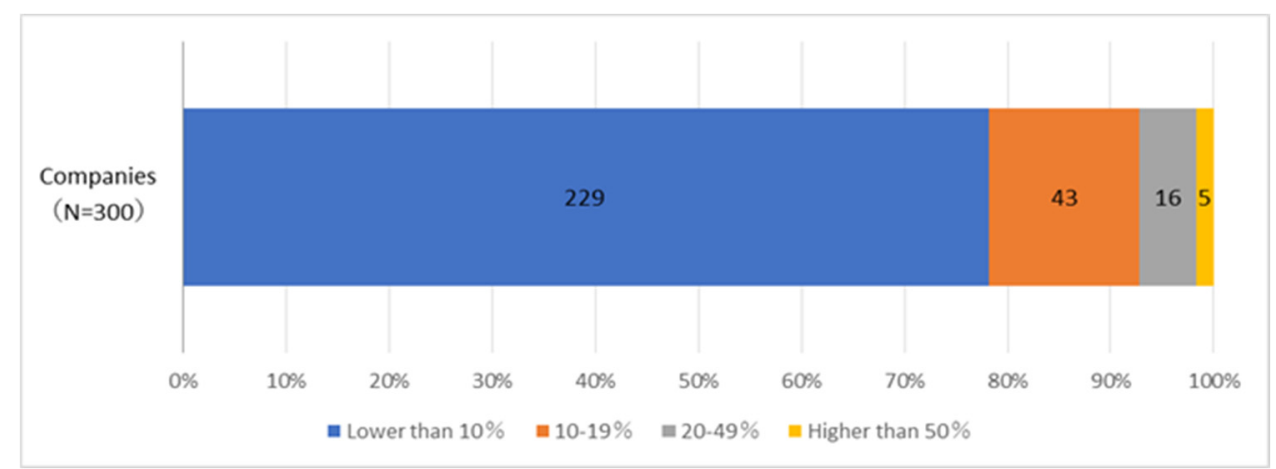

Figure 3: Percentages of elderly employees. 


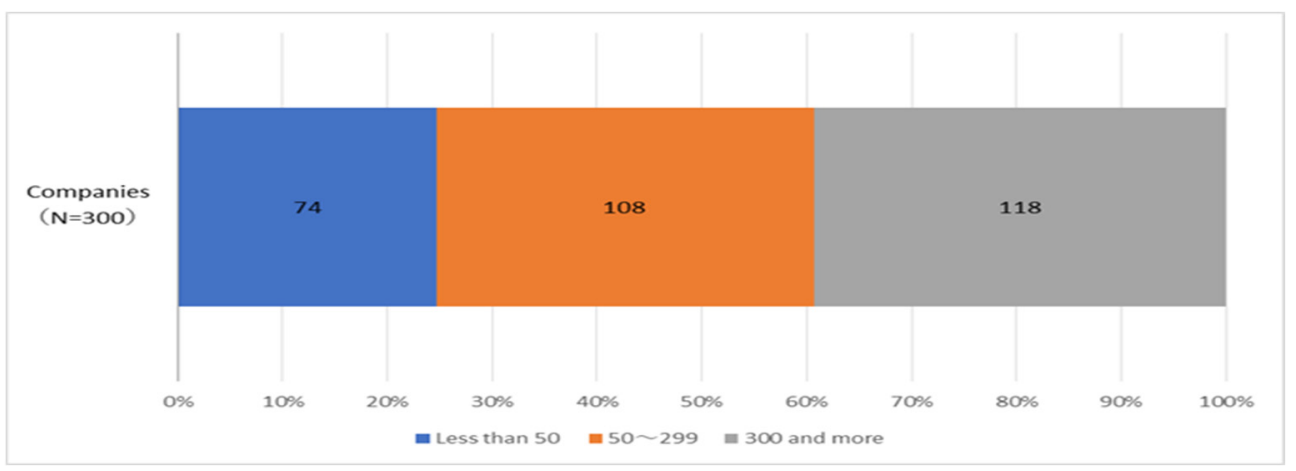

Figure 4: Classification of companies by number of employees.

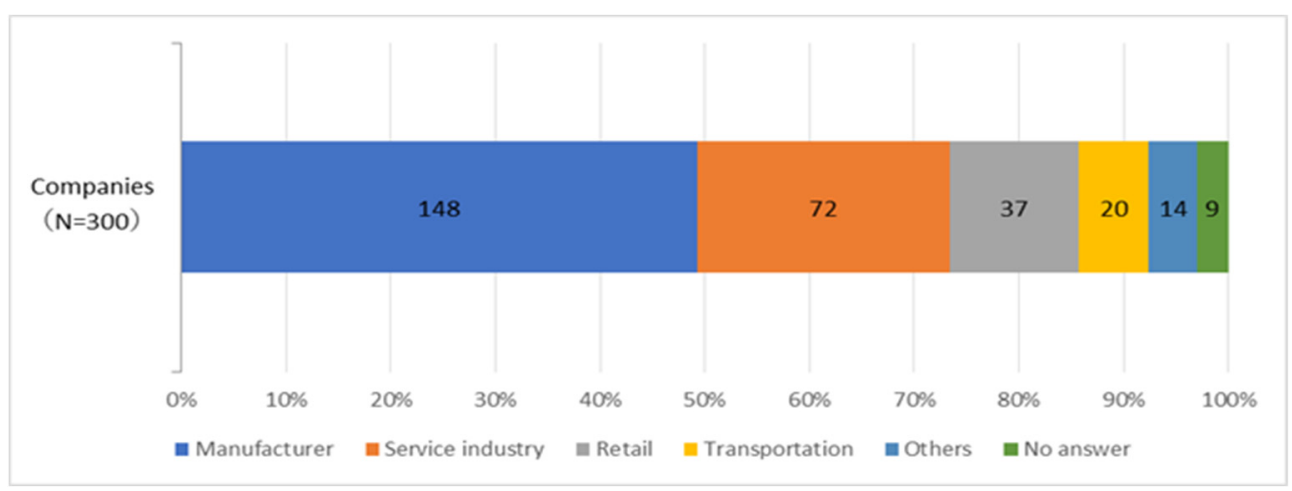

Figure 5: Classification of companies by industry.

Classification of the companies by industry are shown in Fig. 5, nearly half of them were found to be manufacture followed by the service industry and retail both shared higher than $10 \%$ of the total. The manufacturer industry, having the highest share in the total companies, is the representation of Aichi Prefecture. Toyota Motor Corporation and the related suppliers dominates the industry over the whole prefecture.

\section{ABOUT THE CORPORATE SOCIAL RESPONSIBILITY (CSR)}

The companies were asked whether they have been doing something in the viewpoint of the CSR, as summarized in Fig. 6, 253 companies (nearly 85\%), responded with "doing now" and only 12 companies (4\%) responded with "didn't do and won't do". This means that the CSR related activities are getting popular and have already been adopted by many companies.

If we see the responses according to the number of employees as shown in Fig. 7, large scale companies tend to show more positive responses. In the $96 \%$ of the companies there are "300 and more" employees who responded with "doing now" or "considering to do". However, this percentage fell to $88 \%$ if the companies having less than 50 employees.

The responses after classifying the companies into five types as shown in Fig. 8, only the "retail" shows a different trend that is about 15 points less than the other industries with the response "doing now". 


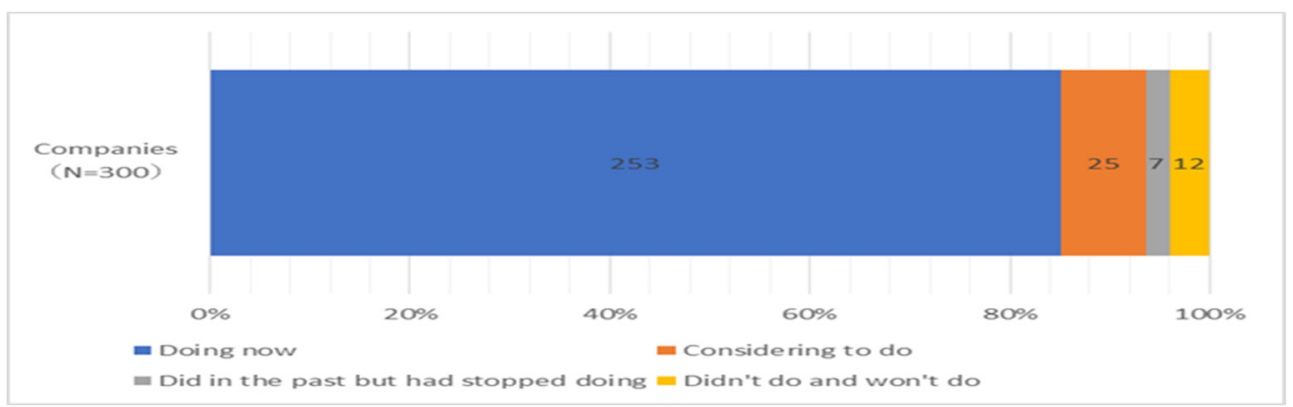

Figure 6: Are you doing something in consideration of CSR?

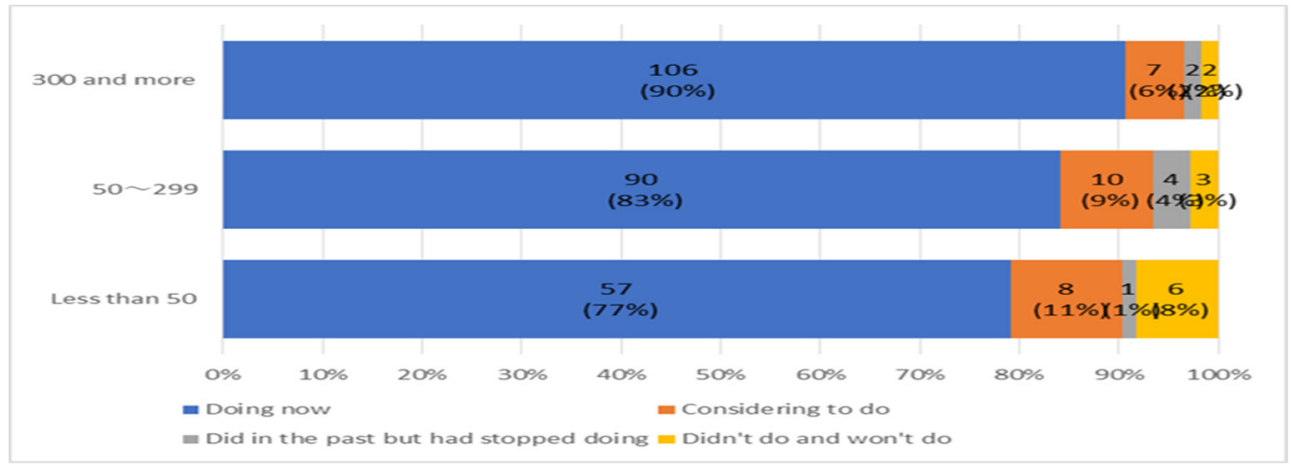

Figure 7: Answers about the CSR by company scale.

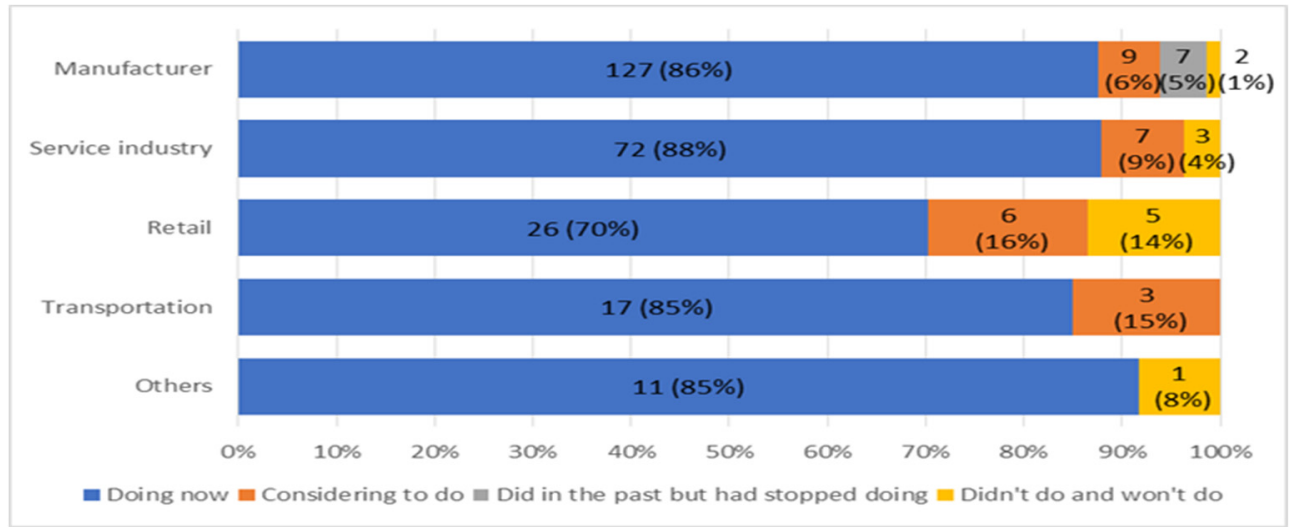

Figure 8: Answers about the CSR by industry.

The companies' responses related to CSR activities with respect to the traffic safety were also recorded, as shown in Fig. 9, more than 50\% responded with "doing now" with assigning "specified staff", "training every year" and taking part in "community activities". 


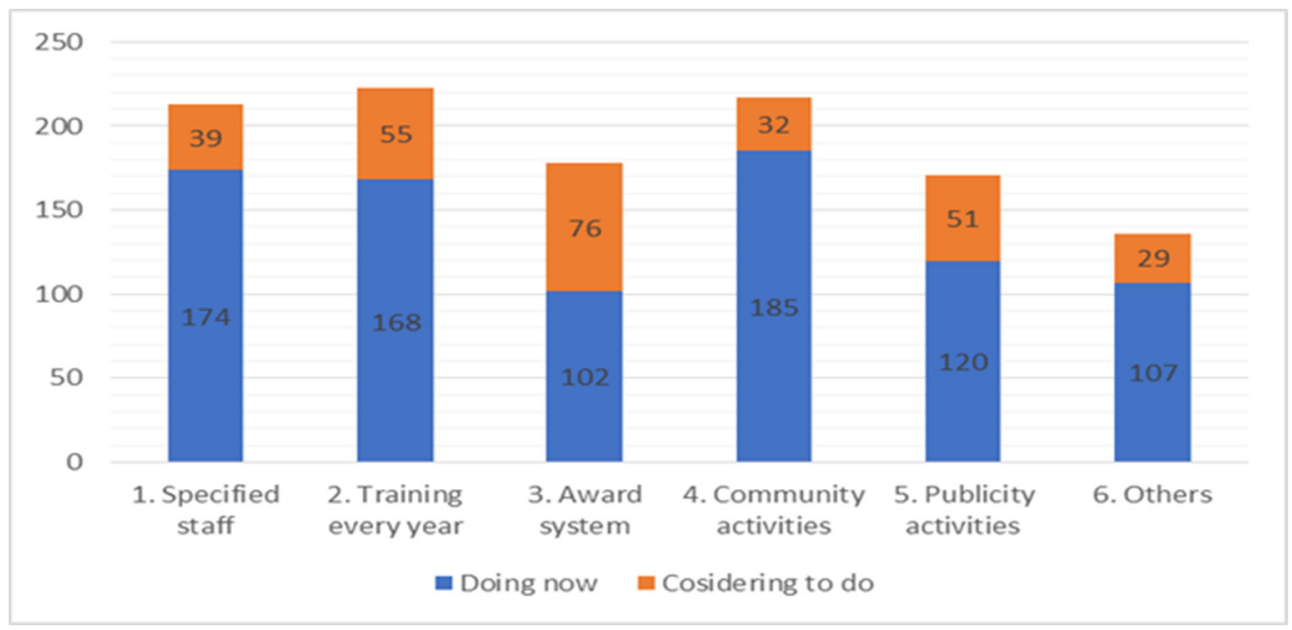

Figure 9: What are doing with respect to the traffic safety as CSR activities?

The companies suggested some of the following good practices and examples related to CSR:

1. The education programs and activities for kids, junior students and elderly drivers are conducted by ten companies.

2. Thirteen companies focus on corporate vehicles: the drive-recorder were equipped with all corporate vehicles; the analysis of employees' driving characteristics were carried out on the basis of the drive-recorder data; monetary benefit are introduced for the employees who have a clean driving record and so on.

\section{ABOUT THE CREATING SHARED VALUES (CSV)}

The companies were asked whether they have been doing something in the viewpoint of the CSV, as summarized in Fig. 10, only 58 companies (nearly 20\%) answered "doing now" but 195 companies (65\%) responded with "didn't do and won't do". Unlike CSR, the CSV related activities have not popularly been taken into consideration.

However, if we see the responses according to the number of employees as shown in Fig. 11, a similar trend with that of the CSR can be observed. That is, large scale companies shew more positive responses. In addition, 32 companies with "300 and more" employees are "doing now", and 15 large scale companies are "considering to do". Adding them together, about $40 \%$ of the large scale companies are positive with the CSV. However, this percentage fell to less than $30 \%$ if the companies having less than 300 employees.

If we check the responses after classifying the companies into five types as shown in Fig. 12, the service industry and the manufacturers show the relatively positive results that are more than $30 \%$ by adding the responses "doing now" and "considering to do". As a good example of the inclusion of CSV in traffic safety practices, products development and providing of services that contribute to traffic safety can be considered. Sixteen companies have developed products that support traffic safety such as school bags with reflective material or good-taste non-alcohol beers etc. While eight companies have provided services like smart phones apps to contact emergency service when traffic accidents occur and also 


\section{Companies}

$$
(\mathrm{N}=300)
$$

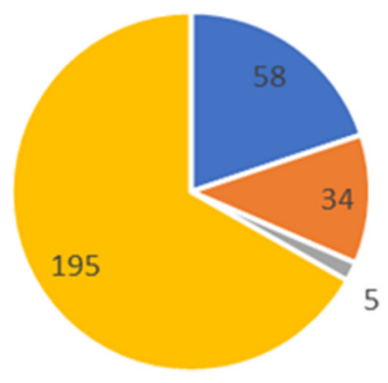

- Doing now

- Considering to do

= Did in the past but had stopped doing $=$ Didn't do and won't do

Figure 10: Are you doing something in consideration of CSV?

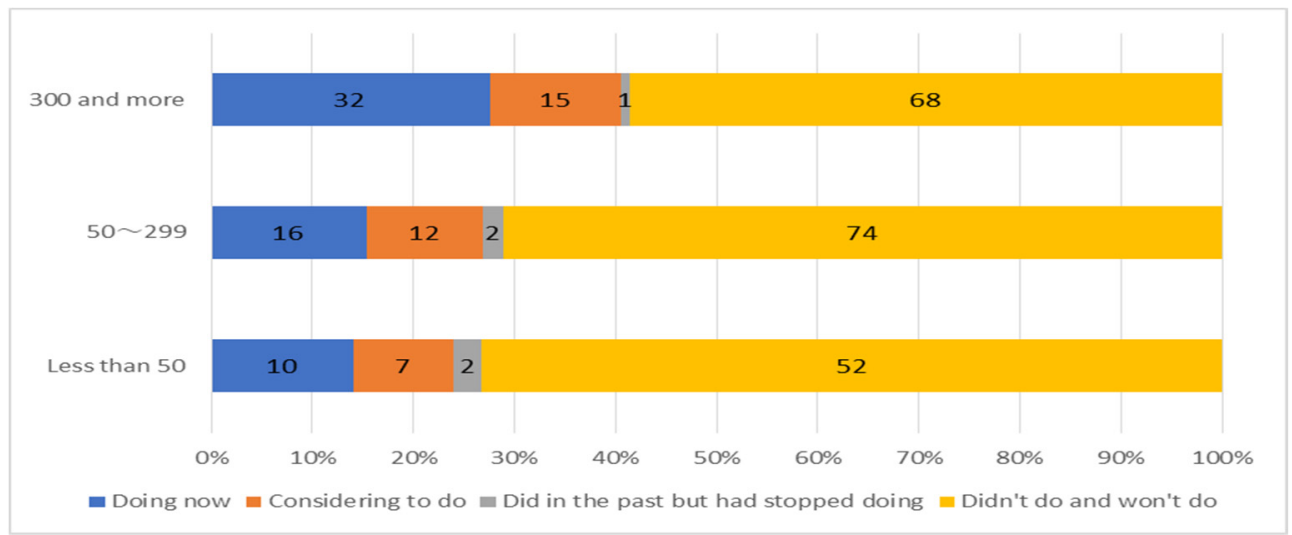

Figure 11: Answers about the CSV by company scale.

insurance cost reduction system based on the traffic safety functions of the vehicle and/or the drivers' behaviour. Good driving behaviours are appreciated with the monetary benefits.

On the other hand, when companies were asked about the possibilities of the CSR and the CSV related activities, shown in Fig. 13, more than $80 \%$ responded with "providing safety education information to employee" as "very good"/"good". Regarding "providing information on effects of ADAS vehicles", "subside to change to ADAS vehicles" and "promoting of CSR and CSV", more than 70\% responded to "very good"/"good". Here ADAS stands for advanced driver-assistance systems. 


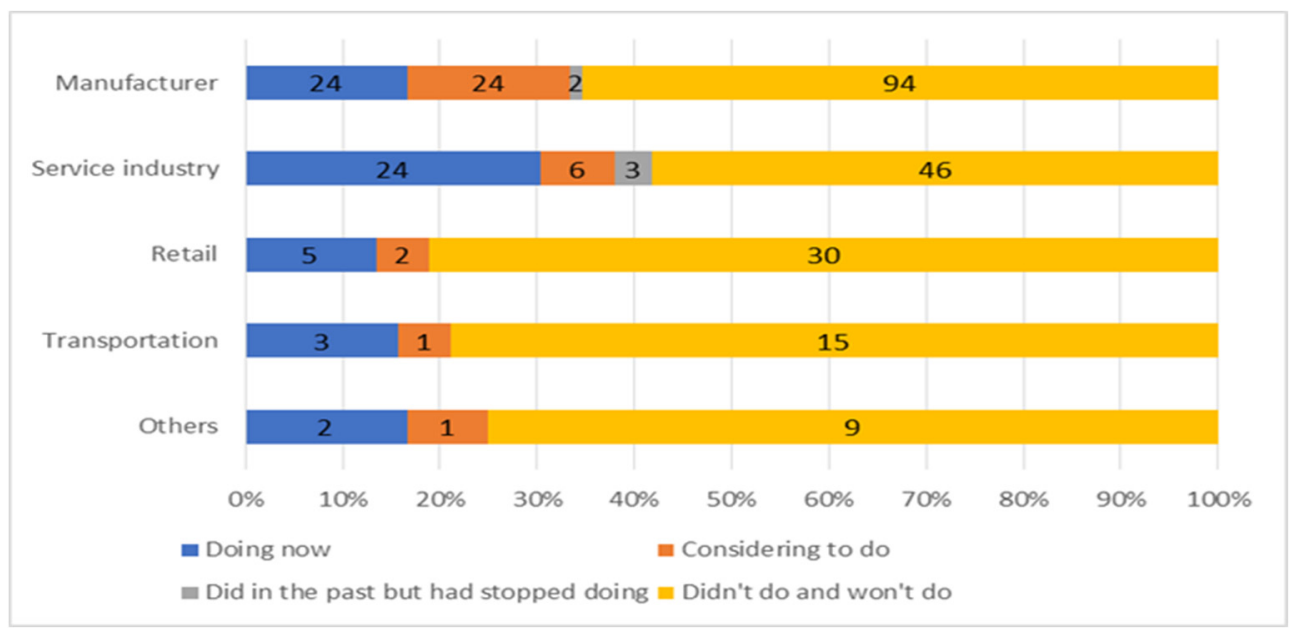

Figure 12: Answers about the CSV by industry.

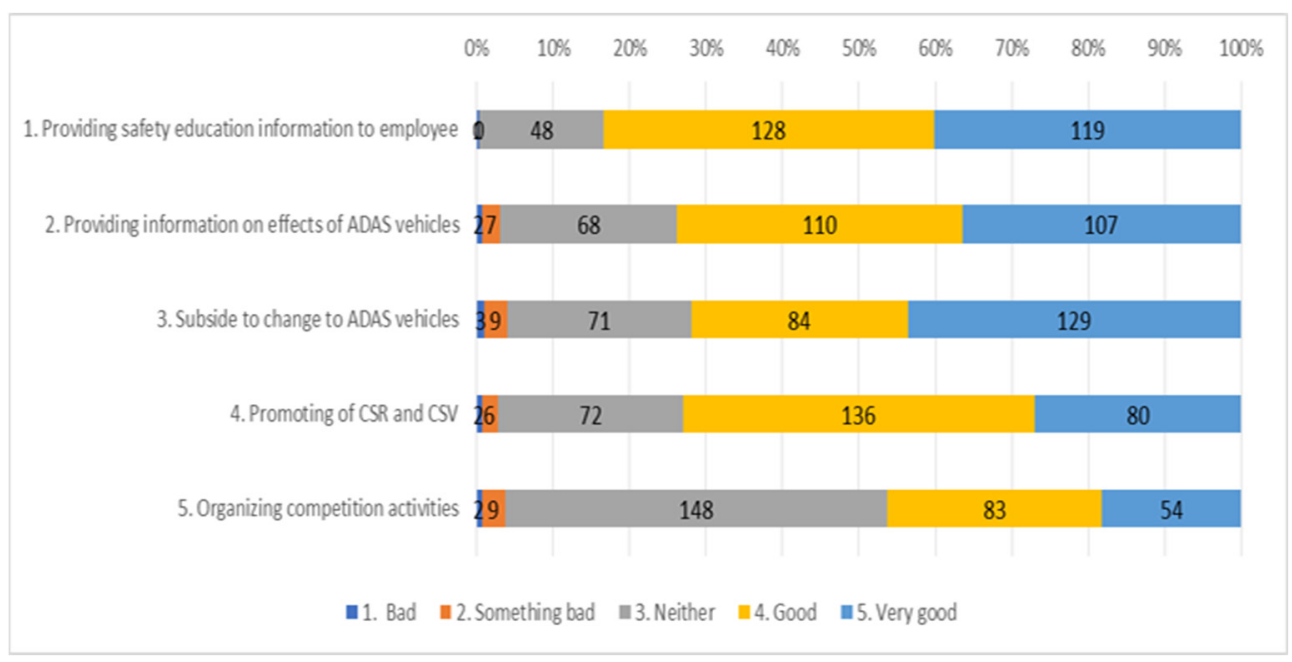

Figure 13: How do you think about activities in consideration of CSR/CSV?

Considering the massively increasing demand of ADAS in Japan, we entailed its consideration with the CSR/CSV activities. As shown in Fig. 14, most people in Aichi use private cars to carry out the daily life activities. In addition to that $59 \%$ of the elderly people (70 years or more) are driving their own private cars and $1 \%$ are driving auto-bikes.

In Japan, as shown in Fig. 15, about 11.5 million of elderly male and 7.2 million of elderly female have the automobile driving licenses (March 2019). It is shown in Fig. 16 that the number of elderly people who return their automobile driving licenses is increasing with each coming year, the number per year is still less than 0.5 million. That count up to only one fortieth of total elderly drivers. Consequently, we can conclude that the solutions in 


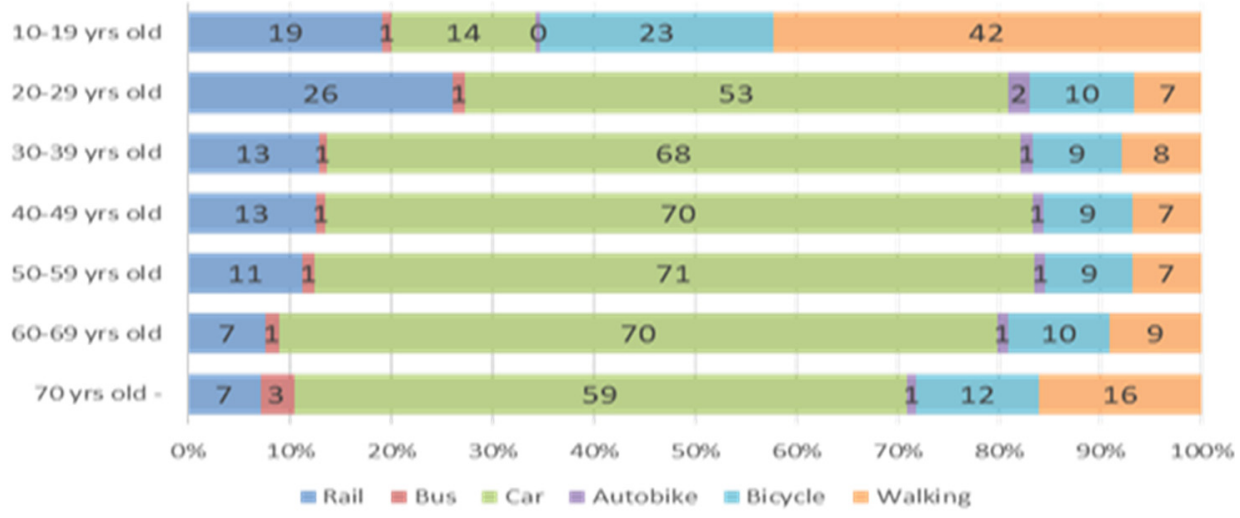

Figure 14: Travel modes by age group in Aichi Prefecture (person trip survey in 2011).

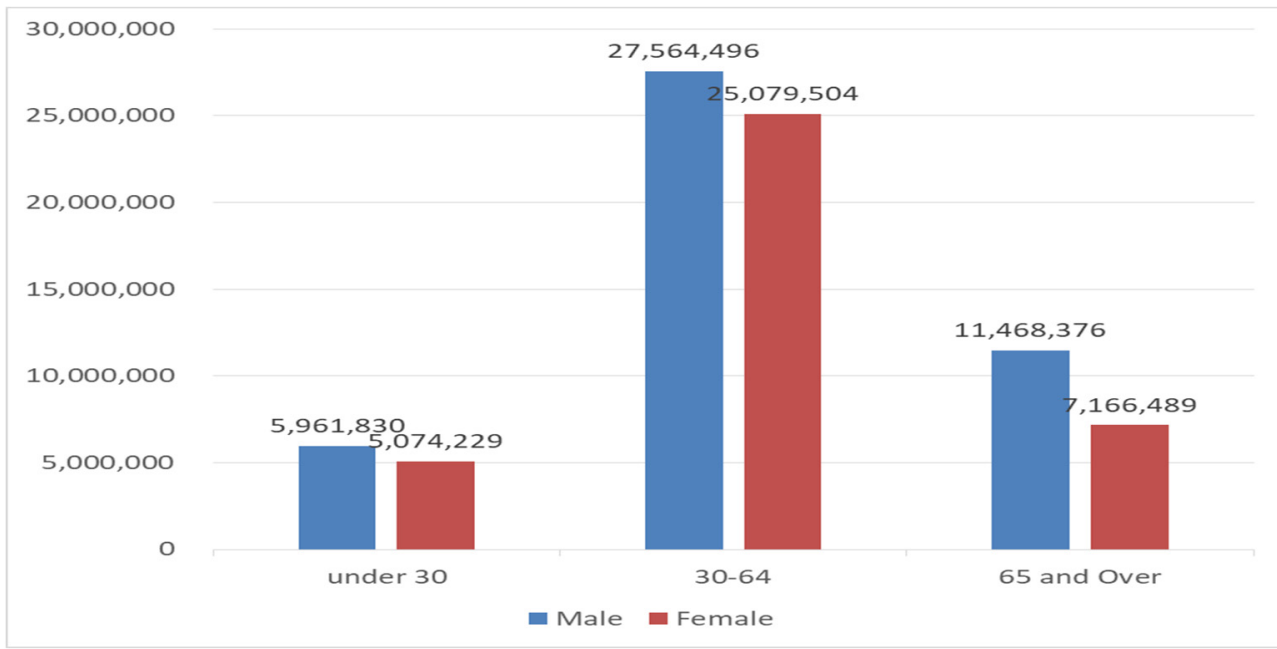

Figure 15: Number of people having driving licenses (March, 2019).

consideration of driving cars are also necessary. Therefore, the alternative policies and traffic safety countermeasure have been discussed from the viewpoint of safer private cars promotions too.

\section{CONCLUSIONS}

Japan being at the forefront of super-aging society requires the effective mobility policies and countermeasures for the elderly people is of paramount importance. Domestically, the traffic safety policy design in Aichi Prefecture is a very serious issue because Aichi had been ranked the worst for the traffic accident fatalities for 17 years by 2018. Meanwhile, Aichi prefecture ranks 1st in Japan for the industrial production amount. Considering the industry power in Aichi, the study summarized in this paper focused on the CSR and CSV so as to find hints or ideas to improve the bad traffic conditions. 


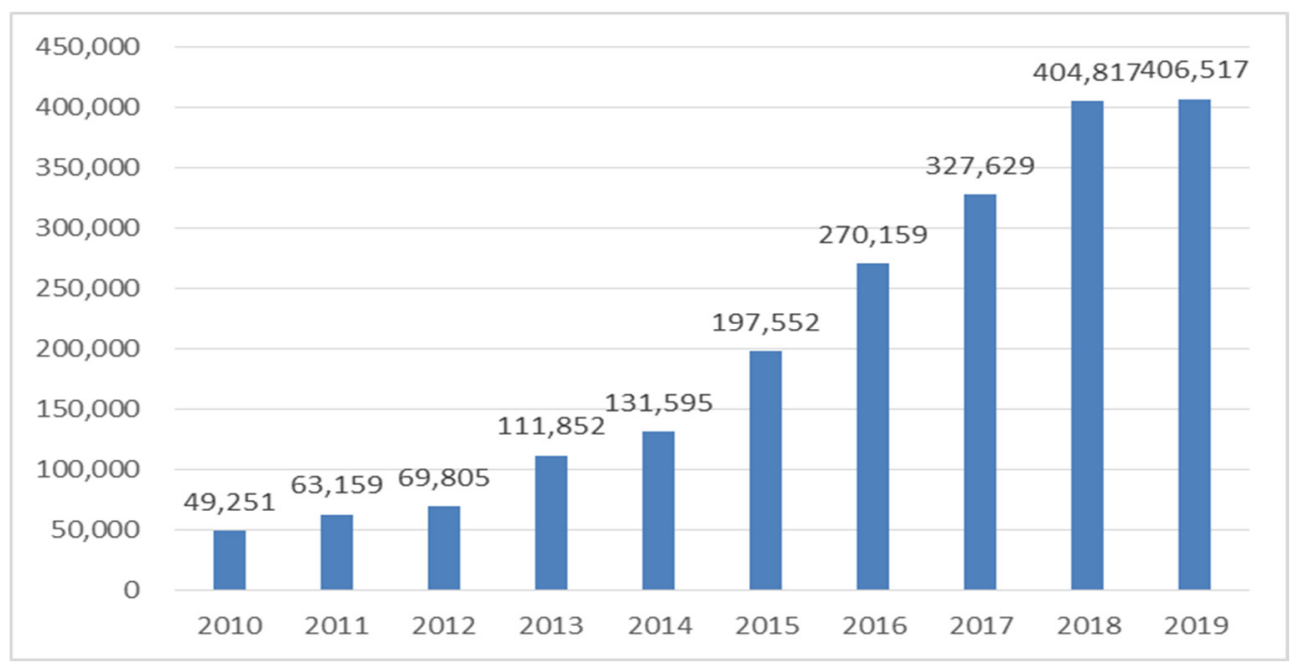

Figure 16: Number of driving licenses returned by elderly people.

In terms of the survey conducted in 2018, many CSR activities such as specifying staff to deal with the traffic safety issue, training employees every year, and taking part in community traffic safety activities have been initiated by many companies. Furthermore, the considerable effective traffic safety countermeasures are summarized as the following:

- $\quad$ providing safety education and information to the employees;

- providing information on effects of the ADAS vehicles;

- $\quad$ subside to change to the ADAS vehicles;

- promoting of the CSR and the CSV.

Especially, regarding the CSV, school bags with reflective material, good-taste nonalcohol beers, smart phones apps for emergency service, and insurance cost reduction system based on the drivers' behaviour can be listed as the good practices. All of the policies and countermeasures summarized in the grand design are expected to be realized in Aichi so as to reduce the traffic accidents by 2030 .

As a memorable result, Aichi has succeeded to quit the status of being the worst prefecture in the traffic accident fatalities ranking in 2019, the first year of the action plan of the grand design. The all other policies and countermeasures planned in the grand design are expected to be implemented continuously.

\section{ACKNOWLEDGEMENTS}

The authors express their deep acknowledgements to Aichi Prefecture Police Headquarters, all members of the committee (chaired by Dr Minoru KAMATA, Honorary Professor of University of Tokyo) and all related organizations, companies and residents in Aichi for their kind supports during the study.

[1] National Police Agency.

\section{REFERENCES}

www.npa.go.jp/publications/statistics/koutsuu/toukeihyo.html, Accessed on: 25 Jun. 2020 . 
[2] Institute for Traffic Accident Research and Data Analysis. www.itarda.or.jp/materials/traffic_accident/free. Accessed on: 25 Jun. 2020.

[3] Aichi Prefectural Police Headquarters, Report on grand design for elderly's traffic safety countermeasures in Aichi Prefecture, 2019. (In Japanese.)

[4] Aichi Prefectural Police Headquarters, References of grand design for elderly's traffic safety countermeasures in Aichi Prefecture, 2019. (In Japanese.)

[5] Shimizu, S. www.think-sp.com/2014/06/15/houritsu-14-koutsuuanzenkyouiku/. Accessed on: 25 Jun. 2020. (In Japanese.)

[6] Aichi Safe Driving Management Association. www.1972-aakk.jp/. Accessed on: 25 Jun. 2020. (In Japanese.)

[7] Ishikawa Prefecture.

www.pref.ishikawa.lg.jp/seikatu/koutsu/annzennunntennsapotosha/ sapocarsyuuryou.html. Accessed on: 25 Jun. 2020.

[8] Aioi Nissay Dowa Insurance. www.aioinissaydowa.co.jp/personal/product/tough/pdf/ tough_kuru_tsunagaru.pdf. Accessed on: 25 Jun. 2020. 